\title{
HIV Infection and Host Genetic Mutation among Injecting Drug-users of Northeastern States of India
}

\author{
Kamalesh Sarkar, Santa Sabuj Das, Reshmi Pal, Baishali Bal, P. Madhusudan, and Sekhar Chakraborti \\ National Institute of Cholera \& Enteric Diseases, P-33 CIT Road, Scheme XM, Kolkata 700 010, India
}

\begin{abstract}
A community-based cross-sectional study was conducted among injecting drug-users (IDUs) of the northeastern states of India to understand the host genetic factors that confer resistance to HIV infection. The study aimed at assessing the existence and magnitude of genetic mutations of chemokine receptors, such as CCR2-64I, CCR-5 D-32, and SDF-1-3'A, that are known to confer resistance to HIV infection and progression of disease in some set-ups. In total, 711 IDUs from Manipur, Mizoram, Nagaland, and Meghalaya were sampled for the study. The selected participants were interviewed to study their sociodemography, risk behaviours, and risk perceptions after obtaining their verbal informed consent. The interview was followed by collection of about $5 \mathrm{~mL}$ of blood samples by an unlinked anonymous method for studying genetic mutation and HIV infection. All the blood samples were transported to and processed at the clinical medicine laboratory of the National Institute of Cholera \& Enteric Diseases, Kolkata, India. The genetic mutations were detected by polymerase chain reaction (PCR) and the restriction fragment length polymorphism (RFLP) assay techniques. The study revealed that 328 (46.1\%) IDUs were aged 20-29 years, 305 (42.9\%) were aged 30 -39 years, and only two (0.3\%) were aged above 49 years. The rate of HIV seropositivity varied widely among the IDUs living in different northeastern states that ranged from $4.5 \%$ to $61 \%$. There was not a single IDU with CCR5 homozygous mutation. Mutated genes of CCR2-64I and SDF-1-3'A were detected in the frequencies of $49 \%$ and $23 \%$ respectively in them. The rate of HIV seropositivity in IDUs having CCR2 mutant gene was $27 \%(n=94)$ and without mutation was $27 \%(n=98)$. Similarly, HIV seropositivity in IDUs with and without SDF1 mutation was $28 \%(n=46)$ and $27 \%(n=146)$ respectively. Both the differences were not statistically significant. A CCR5 homozygous mutation is known to be the most prominent marker that confers resistance against HIV infection. The absence of CCR5 mutant gene in this population suggests that they do not have any additional protection against HIV infection. Analysis also revealed that, although mutation of CCR2 and SDF1 was present in this population, it did not confer any additional resistance against HIV. This indicates that the IDUs of northeastern India are not additionally protected against HIV infection through genetic mutation and are, therefore, vulnerable to acquire HIV infection due to high-risk behaviour and other related factors.
\end{abstract}

Key words: Community-based studies; Cross-sectional studies; Genetic mutation; HIV infections; Sexually transmitted diseases; Substrance-use; India

\section{INTRODUCTION}

HIV continues to be an important public-health problem in India since its first detection in 1986. The national-level prevalence of HIV among adults

Correspondence and reprint requests should be addressed to:

Dr. Kamalesh Sarkar

Deputy Director, Division of Epidemiology [HIV/AIDS]

National Institute of Cholera \& Enteric Diseases

P-33 CIT Road, Scheme XM

Kolkata 700 010, India

and

Officer-in-charge

National Nutrition Monitoring Bureau

West Bengal Unit

Email: kamalesh.sarkar@gmail.com in India is around $0.3 \%$, which gives rise to an estimated 2-3.6 million HIV-infected people in the country (1). The genetic differences between individuals appear to be an essential factor towards protection against HIV infection despite indulgence in high-risk behaviour (2). The risk factors associated with the development of clinical disease and the life-span of HIV infection in individuals are less understood.

Individuals with variants of the genes encoding the chemokine receptors-CCR2 and CCR5-and the ligand SDF1 have been shown to be resistant to HIV-1 infection and progression of disease (3-6). Of the three genetic markers, presence of homozygous CCR5 D-32 allele appears to be the most impor- 
tant factor that confers resistance against HIV-1 infection, and heterozygous mutation prevents the progression of disease (7). The natural resistance to HIV-1 infection has been described by two mechanisms: one is termed 'exposed-uninfected' and the other one 'long-term non-progressors'. In the former type, individuals are exposed repeatedly over a long period without any manifestations of HIV infection. Such individuals include commercial sex workers, people having unprotected sex with infected partners, infants of HIV-positive mothers, IDUs, haemophiliacs, etc. The latter types of individuals carry HIV virus which either does not progress or progresses at a very slow rate. Homosexuals, IDUs, infants, or children usually fall in this group as described by Marmor et al. (8). Such facts have provided several options for research and development of more and more safe and effective drugs and vaccines to combat HIV infection at a very early stage of its pathogenesis.

Of all the northeastern states of India, Manipur in particular is contributing to the rapid spread of HIV-seropositive cases among IDUs (9). Although sharing of injecting equipment and paraphernalia is the main mode of transmission among IDUs here, sexual transmission is also currently increasing there (10). Transmission of HIV in local IDUs has always been viewed as an interaction between behavioural or cultural practices and presence of circulating HIV in the community. Influence of host factors, particularly genetic susceptibility, as mentioned above, has never been thought of and investigated in the said population. Hence, a study was conducted among IDUs of northeastern India to understand the existence and magnitude of genetic variants encoding CCR5, CCR2, and SDF1 and their relationships with the prevalence of HIV infection among them.

\section{MATERIALS AND METHODS}

This community-based cross-sectional study was conducted among 711 IDUs from four northeastern states: Manipur, Nagaland, Mizoram, and Meghalaya. Initially, the purpose of the study was explained to all the participants who were invited to participate voluntarily after obtaining their verbal consent. Ethical clearance was obtained from the ethical committee of the National Institute of Cholera \& Enteric Diseases (NICED) before initiation of the study. Two experienced social workers interviewed the study participants using a fieldtested questionnaire to study their sociodemography, risk behaviour, and risk perceptions about HIV infection. The interview was followed by collection of about $5 \mathrm{~mL}$ blood sample by an unlinked anonymous method for testing HIV and genetic mutation. All the samples were then transported to and processed at the clinical medicine laboratory of the NICED, a national AIDS reference laboratory. The genetic mutations were detected by polymerase chain reaction (PCR) and the restriction fragment length polymorphism (RFLP) assay techniques as described below.

Primers for the amplification of CCR5 (FP: 5' TTA AAA GCC AGG ACG GTC AC 3' and RP: 5' TGT AGG GAG CCC AGA AGA GA 3'), CCR2 (FP: 5' TTG TGG GCA ACA TGA TGG 3' and RP: 5' CTG TGA ATA ATT TGC AGA TTG C 3'), and SDF1 (FP: 5' AAG GCT TCT CTC TGT GGG ATG 3' and RP: 5' GAC AGT CGT GGA CAC ACA TGA T 3') were custom-synthesized from Integrated DNA Technologies (IDT), Inc., USA. DNA was extracted from peripheral blood samples following the standard procedure. Peripheral blood mononuclear cells (PBMCs) were isolated from 100 to $200 \mu \mathrm{L}$ of blood by pelleting down the cells at 1,000 rpm for five minutes. Red blood cells (RBCs) were lysed by re-suspending the cell pellet in $500 \mu \mathrm{L}$ of ACS-buffered saline, followed by incubation at room temperature for 3-4 minutes. Cell suspension was centrifuged at $6,000 \mathrm{rpm}$ for five minutes after the addition of 500 $\mu \mathrm{L}$ of RPMI medium. The pellet containing PBMCs was washed with $500 \mu \mathrm{L}$ of PBS and lysed by the addition of $500 \mu \mathrm{L}$ of DNAZOL (invitrogen-USA). $0.25 \mathrm{~mL}$ of $100 \%$ ethanol was then added to the lysate, and genomic DNA was spooled out with a pipette-tip and transferred to a fresh tube. DNA was washed twice with $0.8-1.0 \mathrm{~mL}$ of $75 \%$ ethanol and dissolved in $100 \mu \mathrm{L} 8 \mathrm{mM} \mathrm{NaOH}$. PCR amplification of the genes under study was done in a $50-\mu \mathrm{L}$ reaction containing $5 \mu \mathrm{L}$ of $10 x P C R$ buffer, $1 \mu \mathrm{L}$ of dNTPs (2.5 mM stock), $0.4 \mu \mathrm{L}$ of each primer (10 $\mu \mathrm{M}$ stock), ng of genomic DNA, and $2.5 \mathrm{U}$ of Taq DNA polymerase. For the amplification of CCR5, the reaction mixture was subjected to denaturation at $94{ }^{\circ} \mathrm{C}$ for five minutes, followed by 35 cycles of denaturation at $94{ }^{\circ} \mathrm{C}$ for 45 seconds, annealing at $62{ }^{\circ} \mathrm{C}$ for 30 seconds, and extension at $72{ }^{\circ} \mathrm{C}$ for one minute. For CCR2, initial denaturation was followed by 35 cycles of denaturation at $94{ }^{\circ} \mathrm{C}$ for one minute, annealing at $56^{\circ} \mathrm{C}$ for 45 seconds, and extension at $72{ }^{\circ} \mathrm{C}$ for one minute. SDF-1 was also amplified for 35 cycles (denaturation at $94{ }^{\circ} \mathrm{C}$ for one minute, annealing at $50^{\circ} \mathrm{C}$ for one minute, and extension at $72^{\circ} \mathrm{C}$ for 1.30 minutes). A final primer extension at $72{ }^{\circ} \mathrm{C}$ for five minutes was allowed in each case before the PCR was stopped. To analyze RFLP for SDF1-3'A, PCR products were digested with MspI restriction enzyme at $37^{\circ} \mathrm{C}$ for 16 hours. RFLP for CCR2-64I was analyzed by digesting the PCR product with BsaB1 for four hours at $65^{\circ} \mathrm{C}$. The digested products were resolved in $3 \%$ agarose gel. All the data, including laboratory test 
results, were edited, entered, and analyzed using the Epi Info software (version 6.04).

\section{RESULTS}

In total, 711 IDUs from four different northeastern states participated in the study. Figure 1 shows that Manipur had the highest number $(n=306,43 \%)$ of the study participants, followed by Mizoram 28\% $(n=199)$, Nagaland 21.9\% $(n=156)$, and Meghalaya $7 \%(\mathrm{n}=50)$. The HIV seropositivity was $62.1 \%$ $(n=190), 4.5 \%(n=9), 11.5 \%(n=18)$, and $8 \%(n=4)$ in IDUs of Manipur, Mizoram, Nagaland, and Meghalaya respectively.

Three hundred twenty-eight (46\%) participants were aged 20-29 years, 305 (43\%) were aged 30-39 years, and 29 (4\%) were aged 19 years or less. HIV seropositivity showed an increasing trend with the increase in age (Fig. 2). males=28.9\%; $\mathrm{n}=668)$. About half $(51.2 \% ; \mathrm{n}=364)$ of them were unmarried, and $34.7 \%(n=247)$ were married. About $6.5 \%(n=46)$ were married but living separately without legal separation. The remaining $3.7 \%(n=26)$ and $3.9 \%(n=28)$ were widows and divorcees respectively. Half $(50.5 \% ; n=359)$ of the study population was literate up to the level of secondary education, followed by primary education $(17.3 \% ; n=123)$. About $36 \%(n=255)$ of the study subjects were unemployed. Other occupation-groups included service-holders, labourers, students, and businessmen in varying frequencies. Spasmoproxyvon was the most frequently-used substance $(59 \% ; n=419)$, followed by heroin $(54 \%$; $\mathrm{n}=384)$ and brown sugar $(15 \% ; \mathrm{n}=109)$.

A sizable number of the IDUs shared their injecting equipment and paraphernalia. Transmission

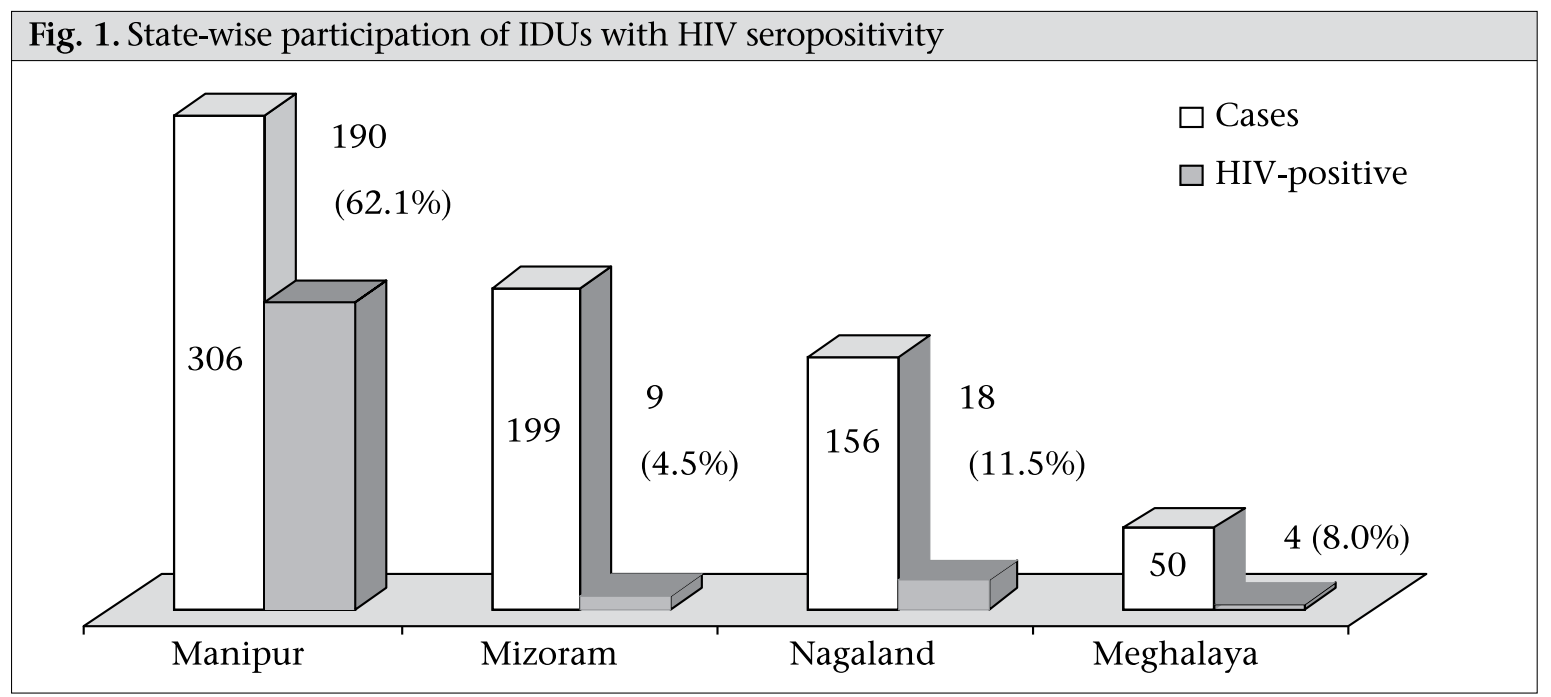

In terms of gender distribution, 94\% $(n=668)$ were male participants while $6 \%(n=43)$ were females. However, the rate of HIV seropositivity in female IDUs was more when compared with their male counterparts (females $=65.1 \% ; n=43$ and of HIV infection is known to be associated with sharing unsafe injection. Table 1 shows that $53.3 \%$ $(n=379)$ of the participants shared their injecting equipment either always or frequently, and the rate of HIV seropositivity in them was $46.7 \%(n=177)$.

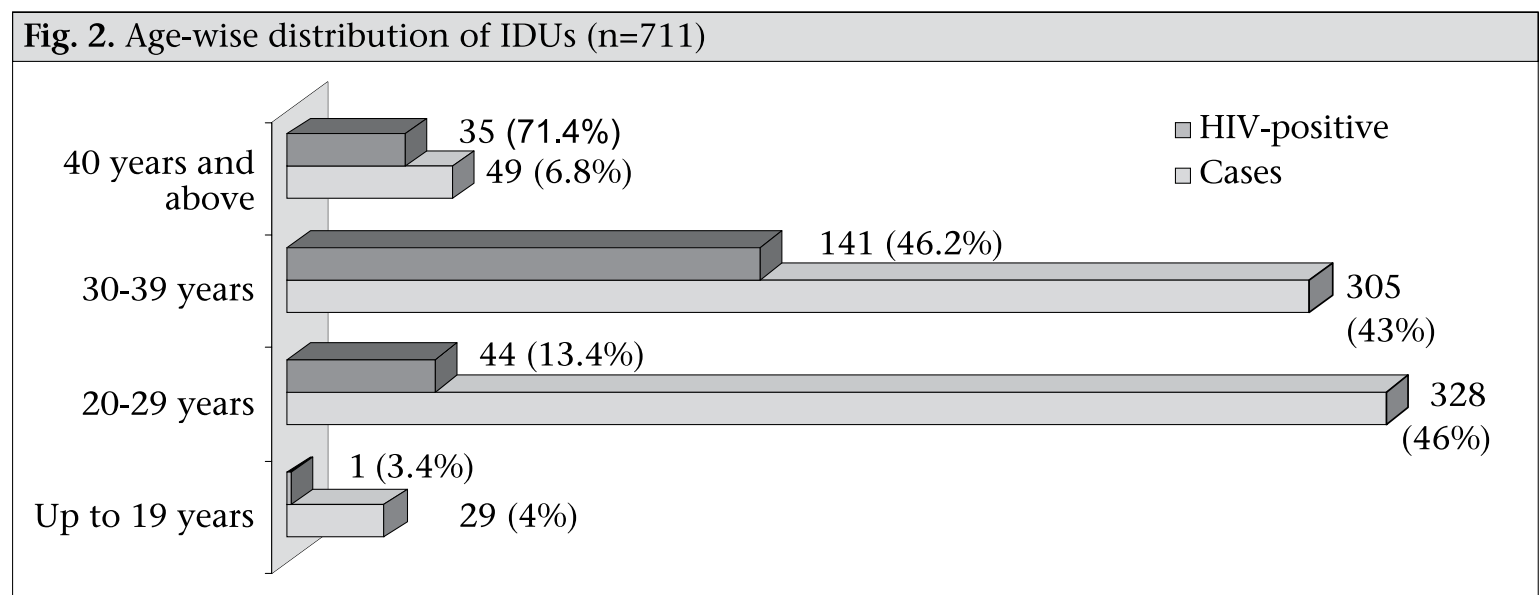




\begin{tabular}{|c|c|c|c|c|c|c|}
\hline \multirow{2}{*}{ Particulars } & \multicolumn{2}{|c|}{ Cases } & \multicolumn{2}{|c|}{ HIV-positive } & \multirow{2}{*}{$\begin{array}{l}\text { Odds ratio } \\
(95 \% \mathrm{CI})\end{array}$} & \multirow{2}{*}{$\mathrm{p}$ value } \\
\hline & No. & $\%$ & No. & $\%$ & & \\
\hline \multicolumn{7}{|l|}{$\begin{array}{l}\text { Frequency of sharing } \\
\text { injecting equipment }\end{array}$} \\
\hline Always/frequently & 379 & 53.3 & 177 & 46.7 & $5.7(3.8-8.5)$ & $<0.05^{*}$ \\
\hline Occasionally/never & 332 & 46.6 & 44 & 13.2 & & \\
\hline \multicolumn{7}{|c|}{$\begin{array}{l}\text { Sharing of drugs from common } \\
\text { ampoules }\end{array}$} \\
\hline Yes & 237 & 33.3 & 150 & 63.3 & $9.79(6.6-14.3)$ & $<0.05^{*}$ \\
\hline No & 474 & 66.7 & 71 & 15.0 & & \\
\hline \multicolumn{7}{|c|}{$\begin{array}{l}\text { Sharing of water for cleaning } \\
\text { syringes before injection }\end{array}$} \\
\hline Yes & 443 & 62.3 & 189 & 42.7 & $5.4(3.5-8.4)$ & $<0.05^{*}$ \\
\hline No & 268 & 37.7 & 32 & 11.9 & & \\
\hline \multicolumn{7}{|c|}{$\begin{array}{l}\text { Sharing of used cotton to stop } \\
\text { bleeding after injection }\end{array}$} \\
\hline Yes & 152 & 21.4 & 62 & 40.8 & $1.73(1.1-2.5)$ & $<0.05^{*}$ \\
\hline No & 559 & 78.6 & 159 & 28.4 & & \\
\hline
\end{tabular}

On the other hand, $46.6 \%(n=332)$ shared either occasionally or never, with an HIV-seropositivity rate of $13.2 \%(n=44)$. This difference was significant as indicated by odds ratio (OR) of 5.7 , with a 95\% confidence (CI) level of 3.8-8.5.

In total, 237 (33.3\%) of the IDUs shared drugs from common ampoules, with an HIV-seropositive rate of $63.3 \%(n=150)$, and $66.7 \%(n=474)$ did not have a similar history of sharing. The HIV-seropositive rate was $15 \%(n=71)$ in them. This difference was significant as indicated by OR of 9.7 and $95 \%$ CI level of 6.6-14.3. $62.3 \%(n=443)$ of the participants shared water for cleaning their syringes before injecting, and the rate of HIV seropositivity was $42.7 \%(\mathrm{n}=189)$ in them. On the contrary, $37.7 \%$ (n-268) did not share, and the rate of HIV sero positivity was $11.9 \%(\mathrm{n}=32)$. This difference was significant indicated by OR of 5.4 and $95 \%$ CI level of $3.5-8.4 .21 .4 \%(n=152)$ shared cotton to stop bleeding following injection with an HIV-seropositivity rate of $40.8 \%(n=62), 78.6 \%(n=559)$ did not share, and the rate of HIV seropositivity was $28.4 \%$ $(n=159)$ in them. The difference was significant with OR of 1.7 and 95\% CI level of 1.1-2.5 (Table $1)$.

There was not a single IDU with CCR5 mutant gene. Distribution of the wild type, heterozygous and homozygous mutations in the CCR2 and SDF1 genes in the study population are shown in Fig. 3.

Table 2 shows the seroprevalence of HIV among IDUs with and without the CCR2 and SDF1 mu- tant genes. However, the difference was not significant ( $>0.05)$.

\begin{tabular}{|lccc|}
\hline \multicolumn{4}{|c|}{$\begin{array}{c}\text { Table } \\
\text { and HIV } \\
\text { andationship between mutated gene }\end{array}$} \\
\hline Mutated gene & $\begin{array}{c}\text { HIV- } \\
\text { positive }\end{array}$ & $\begin{array}{c}\text { HIV- } \\
\text { negative }\end{array}$ & $\begin{array}{c}\text { Total } \\
\text { no. }\end{array}$ \\
\hline $\begin{array}{l}\text { CCR2 } \\
\text { Wild type }\end{array}$ & $98(27)$ & 262 & 360 \\
$\begin{array}{l}\text { Heterozygous } \\
\text { mutated type }\end{array}$ & $86(26)$ & 246 & 332 \\
$\begin{array}{l}\text { Homozygous } \\
\text { mutated type }\end{array}$ & $8(44)$ & 10 & 18 \\
$\begin{array}{l}\text { SDF1 } \\
\text { Wild type }\end{array}$ & $146(27)$ & 400 & 546 \\
$\begin{array}{l}\text { Heterozygous } \\
\text { mutated type }\end{array}$ & $42(28)$ & 106 & 148 \\
$\begin{array}{l}\text { Homozygous } \\
\text { mutated type }\end{array}$ & $4(25)$ & 12 & 16 \\
\hline Figures in parentheses indicte percen & \\
\hline
\end{tabular}

Figures in parentheses indicate percentages

\section{DISCUSSION}

In total, 711 IDUs from four different northeastern states participated in the study. Forty-six percent $(n=328)$ of the participants were aged 20-39 years. The youngest participants $(4 \% ; n=29)$ were aged 19 years or less. HIV seropositivity was increasingly higher with increase in the age of IDUs (Fig. 2). This could be explained by the fact that the older IDUs have a longer duration of injection that could expose them to repeated unsafe injection practices. 


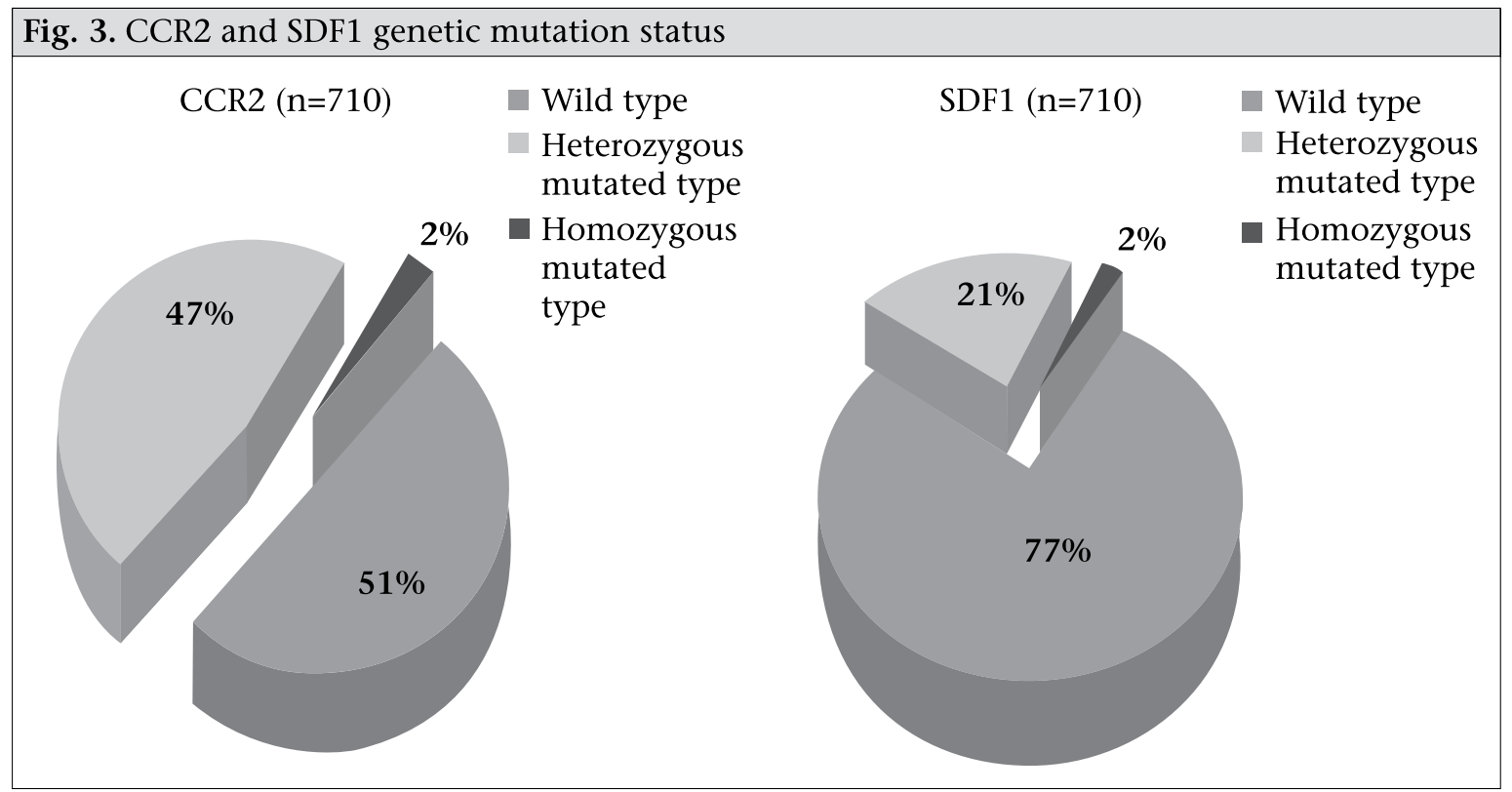

The unsafe injection practices are associated with transmission of blood-borne infection, including HIV, as evidenced by a number of studies $(11,12)$.

The results of the study showed that the female IDUs $(n=43)$ had a higher rate of HIV seropositivity compared to the male IDUs $(n=668)$ as consistent with the findings of a study among IDUs in China (13). In the study community, most (90\%) female IDUs were sex workers. This fact was also consistent with the findings of several other studies among female IDUs where the seroprevalence of HIV was more among female IDUs compared to males (1416). This could probably be explained by the dual route of entry of HIV in female IDUs, who were sex workers too. Unsafe sexual activity was a common risk behaviour encountered with them as observed in other studies $(17,18)$.

Spasmoproxyvon was the highest consumable injectable drug in this part of the country, except parts of Manipur and Nagaland which are traversed by the national highway that acts as the herointrafficking route $(19,20)$. The national highway, which is also considered the heroin-trafficking route, starts from the India-Burma border to Manipur and passes to Nagaland after cutting across the capital city of Manipur, Imphal (21). Consumption of drugs is associated with cultural acceptability, availability, and affordability (11). A study in Bangladesh observed that IDUs usually start addiction with cannabis as the drug of choice and ends up with heroin (22). However, no such diversity in drug-use was observed in the present study.

Unsafe injection-practices are frequently observed in most IDU communities. In this study, HIV seropositivity was observed in $47 \%(n=177)$ and $13 \%$ $(n=44)$ of the IDUs with always or frequent sharing and occasional or no sharing respectively (Table 1). This difference was significant indicated by OR 5.7. This implies that sharing is associated with higher transmission of HIV. Similarly, sharing of drugs from common ampoules, cleaning water, cotton, etc. were associated with higher transmission of HIV among sharers compared to nonsharers. A similar observation was also made in a study of IDUs in a province in China (23).

Several factors that play an important role in the acquisition of HIV infection include viral load at entry-point (set point), the population density, risk behaviour and cultures of a society, immigration and mixing of population, rate of unemployment and poverty, availability, distribution, and consumption of drugs, and government policies (24). Moreover, about 90\% of infected people are not aware that they are carrying the infection, and even if they did, anti-retroviral treatment is not an affordable option for them $(18,25)$. Apart from these factors, host genetics plays an important role in viral entry giving rise to an epidemic. Results of a study showed that people who are homozygous to CCR5 mutation were protected from HIV-1 infection, and on the other hand, heterozygous state renders partial protection against the infection (26).

The HIV epidemic is spreading rapidly in Europe and North America from Asia and Africa due to mutation of HIV subtypes, intermixing of communities, intravenous drug-use, and commercial sex workers $(27,28)$. Thus, genetic mutations need to be considered for the analysis of HIV-1 epidemic in a particular region, apart from risk factors and 
risk behaviours. The mutated gene of CCR5 chemokine co-receptor is a prominent genetic marker of HIV-1 resistance (7). In this study, none of the IDUs had CCR5-mutated gene which is consistent with the finding of another study in diverse populations of Andhra Pradesh, South India (27) and also with the findings of studies in other parts of the world, such as Africa, America, Oceania, South-East Asia, and China (29). As in most parts of the world, the IDUs of northeastern India are not protected by any genetic mutation against HIV infection.

The presence of CCR2 mutation in this study was much higher compared to other studies conducted on diverse populations of Andhra Pradesh, India (29) and in HIV patients of Kuwait (30). On matching unsafe injection-practices, the rate of HIV seropositivity was observed to be almost equal in IDUs with and without CCR2 and SDF1 mutant genes. Since mutation in CCR2 and SDF1 genes slows the progression of HIV, IDUs with absence of these mutated genes might have died earlier than those with mutations. Thus, the former may have been underrepresented in this study, leading to a bias in the results. Also, the study includes IDUs who are currently involved in injection-practices. The history of HIV seropositivity of the past IDUs should also be considered to get a true picture of the effect of host genetic mutation on HIV seroconversion and progression. So, the IDUs of northeastern states of India appear to have no additional protection against HIV-1 infection in absence of CCR5 mutation. Regarding the CCR2 and SDF1 genes, further cohort studies are required to understand whether the existing mutations in these genes confer any additional protection against progression of HIV-1.

The present study has explored the seroprevalence of HIV, injecting practices, and risk behaviours of current IDUs in four northeastern states of India where injection-practices are widespread due to the easy availability of drugs. It also explores the existence and magnitude of genetic mutations of chemokine receptors in the IDUs of the northeastern states to determine their genetic protection to HIV infection and progression. It has documented that unsafe injection-practices are widely prevalent in this part of India and shows significant contribution to the spread of HIV infection. The study also revealed that the IDU population of this region is not additionally protected against HIV infection and its progression through geneticmutation of chemokine receptors, such as CCR2-64I, CCR-5 D-32, and SDF-1-3'A. Unlike some parts of the world where such genetic mutation confers certain amount of protection to HIV infection despite highrisk behaviour, the IDUs in the northeastern states of India need to control unsafe injection and sexual practices to decrease the high prevalence of HIV in these states. Also, further in-depth cohort study needs to be conducted to understand the effects of CCR2 and SDF1 mutation on the progression of HIV infection. Such studies can help us further understand the complex relationship among HIV infection, progression of disease, and host genetic diversity.

\section{REFERENCES}

1. Singh P, Kaur G, Sharma G, Mehra NK. Immunogenetic basis of HIV-1 infection, transmission and disease progression. Vaccine 2008;26:2966-80.

2. Shrestha S, Strathdee S A, Galai N, Oleksyk T, Fallin MD. Behavioral risk exposure and host genetics of susceptibility to HIV-1 infection. J Infect Dis 2006; 193:4-6.

3. Dean M, Carrington M, Winkler C, Huttley GA, Smith MW, Allikmets R et al. Genetic restriction of HIV-1 infection and progression to AIDS by a deletion allele of the CKR5 structural gene. Hemophilia Growth and Development Study, Multicenter AIDS Cohort Study, Multicenter Hemophilia Cohort Study, San Francisco City Cohort, ALIVE Study. Science 1996;273:1856-62.

4. Smith MW, Dean M, Carrington M, Winkler C, Huttley GA, Lomb DA et al. Contrasting genetic influence of CCR2 and CCR5 variants on HIV-1 infection and disease progression. Hemophilia Growth and Development Study (HGDS), Multicenter AIDS Cohort Study (MACS), Multicenter Hemophilia Cohort Study (MHCS), San Francisco City Cohort (SFCC), ALIVE Study. Science 1997;277:959-65.

5. Winkler C, Modi W, Smith MW, Nelson GW, Wu X, Carrington $\mathrm{M}$ et al. Genetic restriction of AIDS pathogenesis by an SDF-1 chemokine gene variant. ALIVE Study, Hemophilia Growth and Development Study (HGDS), Multicenter AIDS Cohort Study (MACS), Multicenter Hemophilia Cohort Study (MHCS), San Francisco City Cohort (SFCC). Science 1998;279:38993.

6. Su B, Jin L, Hu F, Xiao J, Luo J, Lu D et al. Distribution of two HIV-1-resistant polymorphisms (SDF1-3'A and CCR2 64I) in East Asian and world populations and its implication in AIDS epidemiology. Am J Hum Genet 1999;651047-53.

7. Oh DY, Jessen H, Kücherer C, Neumann K, Oh N, Poggensee $\mathrm{G}$ et al. CCR5Delta32 genotypes in a German HIV-1 serconverter cohort and report of HIV-1 infection in a CCR5Delta32 homozygous individual. PLoS One 2008;3:e2747.

8. Marmor M, Hertzmark K, Thomas SM, Halkitis PN, Vogler M. Resistance to HIV Infection. J Urban Health 2006;83:5-17. 
9. Sarkar S, Das N, Panda S, Naik TN, Sarkar K, Singh BC et al. Rapid spread of HIV among injecting drug users in north-eastern states of India. Bull Narc 1993;45:91105.

10. Report of UNGASS 2008 on HIV/AIDS health profile. (http://www.usaid.gov/our_work/global_health/ aids/Countries/asia/india_profile.pdf, accessed on 30 November 2008).

11. Sarkar K, Panda S, Das N, Sarkar S. Relationship of national highway with injecting drug abuse and HIV in rural Manipur, India. Indian J Public Health 1997;41:49-51.

12. Tran TMT, Nguyen HT, Yatsuya H, Hamajima N, Ito ANK. HIV prevalence and factors associated with HIV infection among male injection drug users under 30: a cross-sectional study in Long An, Vietnam. BMC Public Health 2006;6:248.

13. Gu J, Wang R, Chen H, Lau JT, Zhang L, Hu X et al. Prevalence of needle sharing, commercial sex behaviors and associated factors in Chinese male and female injecting drug user populations. AIDS Care 2009;21:31-41.

14. Panda S, Bijaya L, Sadhana Devi N, Foley E, Chatterjee A, Banerjee D et al. Interface between drug use and sex work in Manipur. Natl Med J India 2001;14:20911.

15. Agarwal AK, Singh GB, Khundom KC, Singh ND, Singh T, Jana $S$. The prevalence of HIV in female sex workers in Manipur, India. J Commun Dis 1999;31:238.

16. Strathdee SA, Galai N, Safaiean M, Colantane DD, Vlahov D, Johnson L et al. Sex differences in risk factors for HIV seroconversion among injection drug users: a 10-year perspective. Arch Intern Med 2001;161:12818.

17. Sethi AK, Celantano DD, Gange SJ, Gallant JE, Vlahov D, Farzadegan H. High-risk behavior and potential transmission of drug-resistant HIV among injection drug users. J Acquir Immune Defic Syndr 2004;35:50310.

18. Morrison L. The global epidemiology of HIV/AIDS. $\mathrm{Br}$ Med Bull 2001;58:7-18.

19. Sarkar K, Bal B, Mulherjee R, Chakraborty S, Niyagi SK, Saha MK et al. Epidemic of HIV coupled with hepatitis $C$ virus among injecting drug users of Himalayan West Bengal, Eastern India, bordering Nepal, Bhutan and Bangladesh. Subst Use Misuse 2006;41:341-52.
20. Eicher A.D, Crofts N, Benjamin S, Deutshmann P, Rodger AJ. A certain fate: spread of HIV among young Iiinjecting drug users in Manipur, North-East India. AIDS Care 2000;12:497-504.

21. Beyrer C, Razak MH, Lisam K, Chen J, Lui W, Yu XF. Overland heroin trafficking routes and HIV-1 spread in south and South-East Asia. AIDS 2000;14:75-83.

22. Islam SK, Hossian KJ, Kamal M, Ahsan M. Prevalence of HIV infection in the drug addicts of Bangladesh: drug habit, sexual practice and lifestyle. Int J STD AIDS 2003;14:762-4.

23. Jia Y, Lu F, Zeng G, Sun X, Xiao Y, Lu L et al. Predictors of HIV infection and prevalence for syphilis infection among injection drug users in China: communitybased surveys along major drug trafficking routes. Harm Reduct J 2008 Aug 25;5:29.

24. Gonzalez E, Dhanda R, Bamshad M, Mummidi S, Geevarghese R, Catano G et al. Global survey of genetic variation in CCR5, RANTES, and MIP-1alpha: impact on the epidemiology of the HIV-1 pandemic. Proc Natl Acad Sci USA 2001;98:5199-204.

25. Inciardia JA, Surratt HL, Pechansky F, Kessler F, Von Diemen L, da Silva EM et al. Changing patterns of cocaine use and HIV risks in the south of Brazil. J Psychoactive Drugs 2006;38:305-10.

26. Marmor, M, Sheppard HW, Donnell D, Bozeman S, Celum C, Buchbinder S et al.; HIV Network for Prevention Trials Vaccine Preparedness Protocol Team. Homozygous and heterozygous CCR5-[DELTA] 32 genotypes are associated with resistance to HIV infection. J Acquir Immune Defic Syndr 2001;27:472-81.

27. Pérez-Saleme LM, Hernández-Tepichin G. Epidemiology of HIV infection: twenty-years of experience. Rev Invest Clin 2004;56:134-42.

28. Blair D. AIDS is the most threatening and lethal new epidemic of the twentieth century. From the Advisory Council. Harv AIDS Rev 1998(Fall):1.

29. Su B, Sun G, Lu D, Xiao J, Hu F, Chakraborty R et al. Distribution of three HIV-1 resistance-conferring polymorphisms (SDF1-3'A, CCR2-64I, and CCR5- $\subset$ 32 ) in global populations. European J Hum Genet 2000;8:975-79.

30. Voevodin A, Samilchuk E, Dashti S. Frequencies of SDF-1 chemokine, CCR-5, and CCR-2 chemokine receptor gene alleles conferring resistance to human immuno-deficiency virus type 1 and AIDS in Kuwaitis. J Med Virol 1999;58:54-8. 